\title{
The effect of thrust force in drilling composite materials using step core-ball drill
}

\author{
Hsing-Ming Teng and Chung-Chen Tsao* \\ Tahua University of Science and Technology, Department of Mechatronic Enginering, 30743 \\ Chunglin Hsinchu, Taiwan, ROC
}

\begin{abstract}
Composite materials have gained increasing popularity over the past few decades due to their superior mechanical properties, such as high strength-to-weight ratio, fighting against high temperature and corrosion resistance. The assembly of enormous aeronautical components and structures require the machining of composite materials. Drilling is the most important hole- making process in the final assembly. When drilling composite materials, a number of defects are generating. Delamination caused by drilling thrust has been showed as one of the most problematic defects after drilling composite laminates. With a pressing need for decreased delamination, many studies are turning more and more toward tool geometry and machining parameters. Drilling of composite plates using a step core-ball drill, which is a special drill to improve the chip flow and reduces the thrust force at the exit of hole, is investigated in this study. The experimental results found that the step core-ball drill was efficient in drilling of carbon fiber reinforced plastic (CFRP) and did not produce loading on the drill exit at the proper drilling conditions. The results obtained from this study feeding back for fundamental research efforts could steer future studies on the drilling composite materials in the most promising direction.
\end{abstract}

\section{Introduction}

Composite materials have rapidly increasing popularity over the past few decades because their superior mechanical properties such as high strength-to-weight ratio, fighting against high temperature and corrosion resistance, especially the percentage of carbon fiber reinforced plastics (CFRPs) has reached up to $40 \%$ in the new generation of aircrafts manufacturing [1]. The Dreamliner 787 of Boeing's commercial aircraft, which has $50 \%$ composite (including plastics and carbon fiber) of its primary aircraft structure, is constructed in tubular segments using a molding process that can eliminate 1,500 aluminum sheets and 50,000 fasteners during final assembly [2-3]. Drilling is mostly used for holemaking process in composite parts for final assembly operations. Drilling-induced defects, such microcracking, fiber pullout, delamination, splintering and burr, reduces the hole quality of the machined parts. However, delamination is highly concern during drilling composites due to its inhomogeneity and anisotropic nature. Miner and Mackey point out that not only for new concepts of tooling but also for different realms of cutting conditions to solve the drilling-induced damages in drilling composite materials [4-5]. In general, 
drilling-induced delamination easily occurs both at the entrance (peel-up) and the exit (push-out) sides of the workpiece. Carbon fiber reinforced plastics (CFRPs), which are one of the interest subjects in machining composite materials, are known to be difficult to machine due to the abrasive nature and low thermal conductivity. Many studies have been shown that different techniques can increase drilled quality of composites by changing the configuration of the process such as feed rate, spindle speed, tool geometry and material, coolant type, coated tool, back-up plate, etc. Feed rate and tool geometry, however, are the two most important cutting parameters affecting the quality of drilled holes, and feed rate and drilling-induced thrust force are closely related [6-29]. It has been recommended to set feed high to avoid the peel-up defect while the drill just entrances the workpiece. That action made the high risk on delamination at the exit side of the hole. Additionally, the influence of drilling speed on the hole quality is shown to be minimal than feed rate; therefore, high drilling speed is adopted for better productivity.

The twist drill, which has quite a complicated tool geometry, is a traditionally use tool for hole-making in industrial practice. The chisel edge of the twist drill, which has a null cutting speed at the center point, pushes the uncut thickness (last lamina) as it approach the exit side in drilling. The action of the chisel edge on the thrust force increases with the feed rate and may account for over $80 \%$ of the total force needed to drill a hole. The exit side delamination occurs when thrust force exceeds the inter-laminar bond strength of the composite material. Step core-ball drill, which has a half ball geometry on the end of outer cutting tool, is a special drill to improve the chip flow and reduces the thrust force at the exit of hole in drilling of composite plates, as shown in Fig. 1. Additionally, plated diamond bit plays an increasingly important role in civil, geology, petroleum, construction and other industrial applications. Some researches and enterprises now pay close attention by advantages of plated diamond bit such as high bonding strength, high grit protrusion and large space for chip [30-33]. An experimental analysis for thrust forces associated with the various diamond grits and drilling parameters using step core-ball drill in drilling of composite materials was investigated in the present study. An innovative tool, however, can be consulted in efficiency and quality of drilling composite materials in domestic industry in the future.

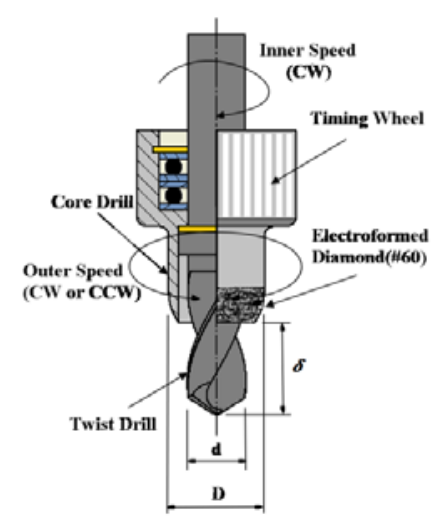

Fig. 1. Schematic of step core-ball drill.

\section{Experimental setup and method}

The composite laminates were fabricated using the prepreg 41C30126 fabric carbon fiber/epoxy matrix (Formosa Plastics Corporation) by autoclave molding. The stacking sequence of the laminates was $[0 / 90]_{8 \mathrm{~S}}$. The carbon fiber reinforced plastic (CFRP) 
laminates were approximately $4.0 \mathrm{~mm}$ thick and 16 plies were laid up. Specimens of $60 \times 60$ $\mathrm{mm}^{2}$ were cut, using a water-cooled diamond table saw. Drilling tests were conducted using a 3-axis LEADWELL V30 vertical machining center with a 5.5-kW spindle drive, for which the thrust force was measured using a Kistler 9273-type piezoelectric dynamometer. The force signals were transmitted to a Kistler 5011 multichannel charge amplifier and stored on a P4 personal computer. The experimental setup to measure thrust forces for step core-ball drilling is shown in Fig. 2. The proper fixture was held rigidly on top of the dynamometer. The outer drill diameter, plated length and core-ball tool thickness of the step core-ball drills are 10,12 and $1 \mathrm{~mm}$, respectively. The end of the core-ball tool plated with \#40 $(0.38 \mathrm{~mm}), \# 50(0.27 \mathrm{~mm})$ and $\# 60(0.25 \mathrm{~mm})$ diamond grits on the cutting surface, which are different in grain size, were used in all tests. The internal part of the step coreball drills is the twist drill. Tungsten carbide twist drills of 5.6 and $6.8 \mathrm{~mm}$ diameter were used to obtain the entire drilling-thrust. All experiments were performed twice, under dry drilling conditions at spindle speeds of 800, 1,000 and 1,200 rpm for outer drills, respectively, spindle speed of 1,214 rpm for inner drill, and feed rates of 15, 18 and 20 $\mathrm{mm} / \mathrm{min}$. In this study, the rotational direction of the inner drill is always clockwise $(\mathrm{CW})$, and the rotational direction of outer drill is always counter clockwise (CCW). The different rotational direction between inner drill and outer drill is shown in Fig. 3.

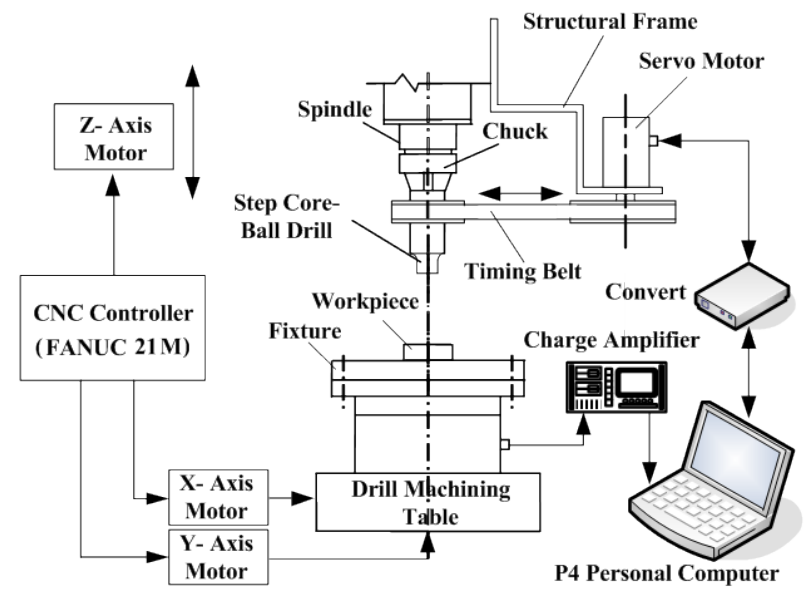

Fig. 2. Schematic diagram of experimental set-up.

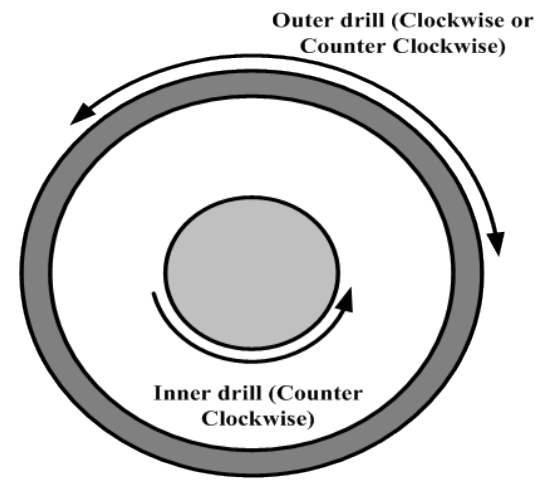

Fig. 3. The different rotational direction between inner drill and outer drill for step coreball drill (Bottom View). 


\section{Results and discussions}

Fig. 4 depicts the thrust force of step core-ball drill with a $1000 \mathrm{rpm}$ spindle speed at various plated diamond grits and feed rates in drilling CFRP. From Fig. 4, the thrust forces of step core-ball drill with various plated diamond grits increases as the feed rate increases. Numerous papers have recognized that thrust force (or delamination) increases with feed rate $[5,8-10,28]$. For minimizing drilling-induced damage, low feed rate is preferred in drilling of composite laminates. The thrust force with \#60 plated diamond grit is larger than thrust force with \#40 plated diamond grit as shown in Fig. 4. This result may be explained by the fact that the thrust force at the exit section when the \#60 plated diamond grit core drill was used became large due to the variation of the total contact area between plated diamond grits and machined surface. From these experiments, it may be concluded that the larger plated diamond grit of core drill is appropriate for the CFRP drilling without fuzzing and delamination. The study experimentally explains how the plated diamond grit significantly affects the thrust force in drilling composite materials. Fig. 5 depicts the thrust force of step core-ball drill with an $18 \mathrm{~mm} / \mathrm{min}$ feed rate at various plated diamond grits and rpm spindle speeds in drilling CFRP. From Fig. 5, the thrust forces of step core-ball drill with various plated diamond grits decreases as the spindle speed increases, which might be explained by the fact that the epoxy resin of the CFRP was damaged by the heat generated due to the increase of cutting speed. Also, numerous papers have proved that thrust force (or delamination) decreases with spindle speed.

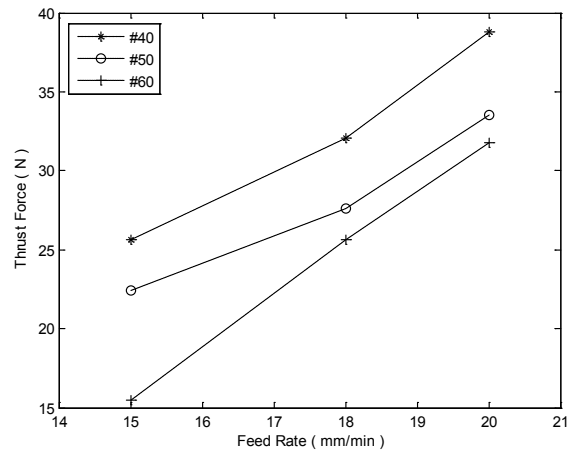

Fig. 4. Thrust force of step core-ball drill with a $1000 \mathrm{rpm}$ spindle speed at various plated diamond grits and feed rates in drilling CFRP.

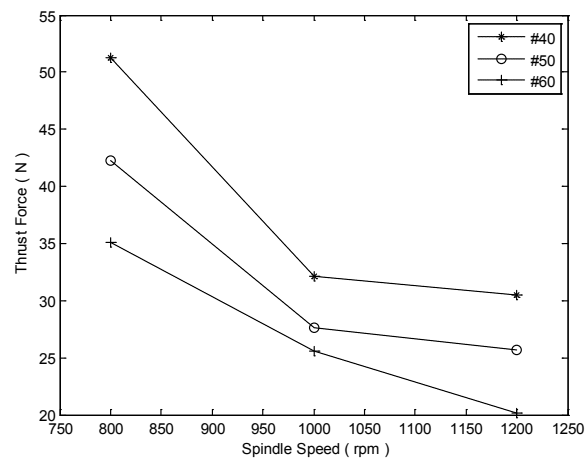

Fig. 5. Thrust force of step core-ball drill with an $18 \mathrm{~mm} / \mathrm{min}$ feed rate at various plated diamond grits and spindle speeds in drilling CFRP. 


\section{Conclusions}

An experimental analysis for thrust forces associated with the various plated diamond grits and drilling parameters using step core-ball drill in drilling of composite materials is investigated in the present study. The results reveal that, the thrust force of the step coreball drill with \#40 plated diamond grit is lower than those with \#60 plated diamond grit. In other words, the larger plated diamond grit can cause larger thrust force at the step core-ball drill exit in the workpiece. However, a increase in feed rate at the end of drilling using step core-ball drill in drilling of composite materials will cause the cracking around the exit edge of the hole. It was also stated that the larger the feeding load is, the larger the thrust force is.

\section{Acknowledgment}

The research is partially supported by Ministry of Science and Technology, Taiwan, ROC, under contract MOST-105-2221-E-233 -001.

\section{References}

1. Y. Karpat, O. Bahtiyar, B. Değer, B. Kaftanoğlu, CIRP Ann. 63(1), 81 (2014)

2. http://www.dailymail.co.uk/sciencetech/article-2041863/Boeing-787-Dreamliner-realitycarbon fibre-plane-delivered-Japan.html

3. https://www.thoughtco.com/boeings-787-dreamliner-820385

4. L.H. Miner, EI Segundo California, Soc. Plast. Eng. 85 (1980)

5. B.A. Mackey, Proc. $37^{\text {th }}$ Conf. Soc. Plas. Ind., Reinf. Plast./Compos. Institute, 1 (24D), (1982)

6. W. König, C. Wul, P. Grass, H. Willerscheid, CIRP Ann. 34(2), 537 (1985)

7. I. El-Sonbaty, U.A. Khashaba, T. Machaly, Compos. Struct. 63, 329 (2004)

8. H. Hocheng, C.K.H. Dharan, ASME J. Eng. Ind. 112, 236 (1990)

9. H. Hocheng, C.C. Tsao, J. Mater. Process. Technol. 140, 335 (2003)

10. H. Hocheng, C.C. Tsao, J. Mater. Process. Technol. 167, 251 (2005)

11. H. Hocheng, C.C. Tsao, Int. J. Mach. Tools Manuf. 46, 1403 (2006)

12. C.C. Tsao, Int. J. Mach. Tools Manuf. 46, 1653 (2006)

13. M. Fernandes, C.Cook, Int. J. Mach. Tools Manuf. 46, 70 (2006)

14. M. Fernandes, C. Cook, Int. J. Mach. Tools Manuf. 46, 76 (2006)

15. S. Jain, D.C.H. Yang, ASME J. Eng. Ind.. 116, 475 (1994)

16. U.A. Khashaba, M.A. Serif, M.A. Elhamid, Compos. Part A Appl. Sci. Manuf. 38, 61 (2007)

17. W. König, P. Grab, CIRP Ann. 38(1), 119 (1989)

18. A. Koplev, A. Lystrup, T. Vorm, Compos. 14, 371 (1983)

19. R. Piquet, B. Ferret, F. Lachaud, P. Swider, Compos. Part A Appl. Sci. Manuf. 31, 1107 (2000)

20. C.C. Tsao, H. Hocheng, Int. J. Mach. Tools Manuf. 44, 1085 (2004)

21. C.C. Tsao, H. Hocheng, Int. J. Mach. Tools Manuf. 45, 1261 (2005)

22. C.C. Tsao, Int. J. Mach. Tools Manuf. 46, 1653 (2006)

23. C.C. Tsao, H. Hocheng, Int. J. Mech. Sci. 49, 983 (2007)

24. C.C. Tsao, Mater. Des. 29, 1740 (2008)

25. C.C. Tsao, Y.C. Chiu, Int. J. Mach. Tools Manuf. 51, 740 (2011)

26. C.C. Tsao, H. Hocheng, Y.C. Chen, CIRP Ann. 61(1), 91 (2012)

27. M.S. Won, C.K.H. Dharan, ASME J. Manuf. Sci. Eng.124, 242 (2002) 
28. C.C. Tsao, W.W. Wu, Int. J. Computer. Integr. Manuf. 27, 979 (2014)

29. U.A. Khashaba, A.A.El-Keran, J. Mater. Process. Technol. 249, 415 (2017)

30. Y.Q. Xing, J.X. Deng, G D. Zhang, Z. Wu, F.F. Wu, J. Manuf. Process. 26, 31 (2017)

31. W.Y. Song, F.B. Liu, C.G. Bu, G.D. Zhou, Procedia Eng. 73, 48 (2014)

32. I. Sultana, Z. Shi, M.H. Attia, V. Thomson, Procedia CIRP 45, 23 (2016)

33. P.C. Priarone, M. Robiglio, R. Melentiev, L. Settineri, Procedia CIRP 66, 181 (2017) 